\title{
Calculation of Axial Compression Capacity for Square Columns Strengthened with HPFL and BSP
}

\author{
Hua Huang, Kailin Xi, Yu Zhang, Jinghui Shi, and Boquan Liu \\ School of Civil Engineering, Chang'an University, Xian, Shaanxi 710061, China \\ Correspondence should be addressed to Kailin Xi; xikailin@hotmail.com
}

Received 24 September 2015; Revised 14 December 2015; Accepted 27 December 2015

Academic Editor: Seung-Jun Kwon

Copyright ( 2016 Hua Huang et al. This is an open access article distributed under the Creative Commons Attribution License, which permits unrestricted use, distribution, and reproduction in any medium, provided the original work is properly cited.

\begin{abstract}
The load carrying capacity and failure mechanism of 8 square columns strengthened with high-performance ferrocement laminate (HPFL) and bonded steel plates (BSP) were analyzed on the basis of experiments on the axial compression performance of these columns. Results show that the reinforcing layer worked together with the original columns as a whole, and the load-bearing capacity significantly increased. When failure of the strengthened column occurred, the mortar and concrete were crushed and bulged outward in the middle of the columns, the angle bars and longitudinal steel bars buckled, and some stirrups were pulled out. The chamfering of angle bar momentously affected the primary damage of steel strand. The values of the strength reduction factor and pressure effective utilization coefficient of the mortar were suggested. Based on the experiments and existing tests of 35 columns strengthened with HPFL, equations for the axial compression bearing capacity were proposed and all calculation results agreed well with testing results. Therefore, the calculation method could be used in the capacity design of axial compression strengthened columns.
\end{abstract}

\section{Introduction}

New technology for rehabilitating reinforced concrete (RC) structures has continued to emerge recently. Our research group introduced the reinforcement technique strengthened with HPFL and BSP; this technique adopts the advantages of HPFL reinforcement and bonded reinforcement technology [1-3]. At the beginning of this technique, holes on the part of column surface of steel plate position were repaired following the design requirements; other parts of the column were chamfered and scabbled according to the design requirement. Next, structure adhesive was used to stick the steel plate on the RC member surface. Afterwards, the RC member was cleaned, and then high-strength strand was twined around column and fixed on by bolts. Interfacial agent was sprayed and high-performance mortar was plastered after the structure adhesive was solidified. Finally, the strengthened column was cured. This new technique was adapted from reinforcement methods that use HPFL and BSP. Ferrocement is a form of thin wall RC using wire mesh (small diameter skeletal steel rods might be used sometimes) and mortar, and it was thought to be a ductile and durable repair material for RC structures [4-12]. The advantages of the new structure reinforcement technique were that the thickness of reinforced layer was only $25 \mathrm{~mm}$, the influence on the shape of the structure was relatively small, and heavy construction machineries were unnecessary. Furthermore, high-strength steel strand as a reinforcing stirrup could fix steel plates. The bolts for fixing the steel strand served as shear connectors to avoid the slip between the reinforcement layer and the $\mathrm{RC}$ members. As the covering of the steel plate, the highperformance mortar could prevent or delay corrosion. The structure of the reinforced layer, which is composed of pasting steel plate, steel strand by bolts, and plastering mortar, could work together with the original columns as a whole to avoid early stripping damage.

Numerous experimental tests and finite element analyses have been conducted to study the axial force bearing capacity for a concrete column strengthened with FRP [13, $14]$, steel jacket $[15,16]$, and wire mesh [17] by researchers all over the world. However, studies that focus on square columns strengthened with HPFL and BSP are limited. This 
TABLE 1: Material strength of samples (MPa).

\begin{tabular}{lcccccc}
\hline \multicolumn{2}{c}{ Ф6 rebar } & \multicolumn{2}{c}{ Ф12 rebar } & Strand & \multicolumn{2}{c}{ Angle } \\
$f_{y}$ & $f_{u}$ & $f_{y}$ & $f_{u}$ & $f_{u}$ & $f_{y}$ & $f_{u}$ \\
\hline 408.81 & 651.77 & 368.05 & 572.12 & 1606 & 517.80 & 796.50 \\
\hline
\end{tabular}
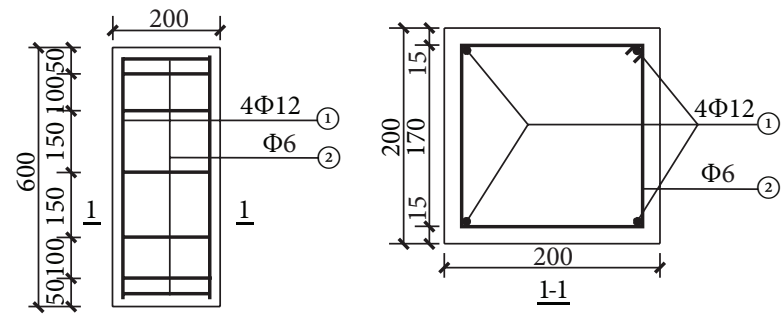

FIGURE 1: Dimensions and reinforcing bars of the columns (unit: $\mathrm{mm})$.

paper reports on the load carrying capacity for strengthened columns through a study carried out on 8 axially loaded $\mathrm{RC}$ columns combined with the obtained test results of 35 specimens. The relative calculation equation is also proposed.

\section{Experimental Program}

In our experiments, 3 concrete square columns and $5 \mathrm{RC}$ square columns strengthened with HPFL and BSP were built. The dimensions and reinforcement bars are shown in Figure 1, and the strengthening design of the column is shown in Figure 2. RG-JS polymer mortar, Araldite XH130AB concrete interface bound rubber, bisphenol A-type modified epoxy resin, and amine curing agent were used in this study. The diameter of the steel strand for reinforcement was $3.2 \mathrm{~mm}$, and its cross-sectional area was $5.1 \mathrm{~mm}^{2}$ and elastic modulus was $1.16 \times 10^{5} \mathrm{MPa}$. The size of the angle was $25 \mathrm{~mm}$ $\times 25 \mathrm{~mm} \times 3 \mathrm{~mm}$, and its cross-sectional area was $143.2 \mathrm{~mm}^{2}$ and elastic modulus was $2.10 \times 10^{5} \mathrm{MPa}$, similar to those of steel. The yield strength of steel $f_{y}$ and the ultimate strength $f_{u}$ are shown in Table 1 , and the cube strength of concrete $f_{\mathrm{cu}}$ and mortar $f_{\mathrm{mu}}$ is shown in Table 2.

\section{Test Results}

The classification of strengthened columns and the main test results are shown in Table 2 . Hydraulic press of $2000 \mathrm{kN}$ was used in the axially compressed experiment. The loading rules were as follows: $60 \mathrm{kN}$ was added per level in initial loading steps; then, $120 \mathrm{kN}$ was added after cracking; finally, the load was decreased back to $60 \mathrm{kN}$ as soon as the load reached $80 \%$ of the ultimate strength. As shown in Table 2, the ultimate bearing capacity for the strengthened column $\mathrm{Z} 1$ increased by $22.13 \%$ compared with column Z02. However, the range of bearing capacity improvement was small, because the mortar strength was only $13.80 \mathrm{MPa}$ after 2 days of curing, considering the early strength properties of mortar. The ultimate bearing capacity for the strengthened columns Z2$\mathrm{Z} 4$ increased by $35 \%-45 \%$ after 5 days of curing; their mortar strength was $32.61 \mathrm{MPa}$ and was close to the concrete strength. The ultimate bearing capacity for the strengthened columns Z5-Z6 increased by $48 \%-52 \%$ compared with unreinforced column Z01. Thus, the strengthening effect was significant. The results indicated that the ultimate bearing capacity for the strengthened column increased with the increase of the ratio of reinforcement and the strength of the polymer mortar, whereas the ductility decreased to some extent.

The load-deformation curve of the strengthened column is shown in Figure 3. The break time of the unreinforced column Z01 was short, the ductility and deformation capacity were poor, and the characteristic of brittle failure was obvious. Given the reinforcement skeleton, the ultimate axial compressive capacity for column Z02 increased by $12.96 \%$, the ductility increased obviously, and the descending part of the load-deformation curve was smooth. Therefore, the ultimate bearing capacity, ductility, and deformation capacity for the strengthened column all increased. This increase was due to the improvement of the compressive strength of the core concrete; such improvement was caused by the active constraints of the lateral deformation in the core concrete by the reinforced layer.

The typical failure modes of the strengthened columns are shown in Figure 4. Cracks formed mainly along the bolts in the vertical direction of the columns when columns were damaged, and the mortar and concrete were crushed and bulged outward in the middle of the columns. Moreover, all the steel strands in the middle part of the angle were cut off, and the four corner angles tended to be stripped because of the loss of the steel strand constraints. The specimens broke suddenly as a result of the sudden unloading of the steel strands. The load of the strengthened columns decreased rapidly at the later steps of loading, which indicated poor member ductility. This characteristic was also shown on the load-deformation curves. Therefore, to improve the late ductility and deformation capacity for the strengthened columns, the sudden cutting off of the steel strands was slowed by increasing the chamfer radius of external angle and sticking steel plates in the column edge after chamfering.

\section{Discussion of Influence Factors of Bearing Capacity of Strengthened Column}

Given the use of reinforcement materials, including highstrength steel strand, angle bar, and high-performance mortar, and the use of shear bolts in the angle bars, the integrity and interoperability between the reinforced layer and the original column were improved. In addition, the reinforced layer restrained the core concrete effectively. Accordingly, the compressive strength of core concrete was improved. The bearing capacity for strengthened columns was affected by the following factors.

4.1. Bearing Capacity of the Original Column. The ultimate bearing capacity for the strengthened columns increased evidently with the increase of the concrete strength of the original component. However, in accordance with certain 


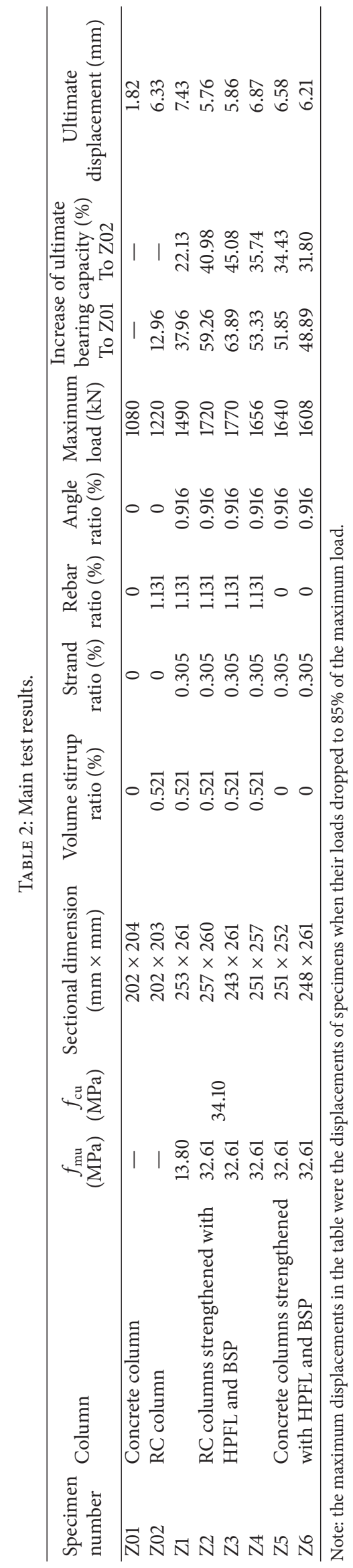



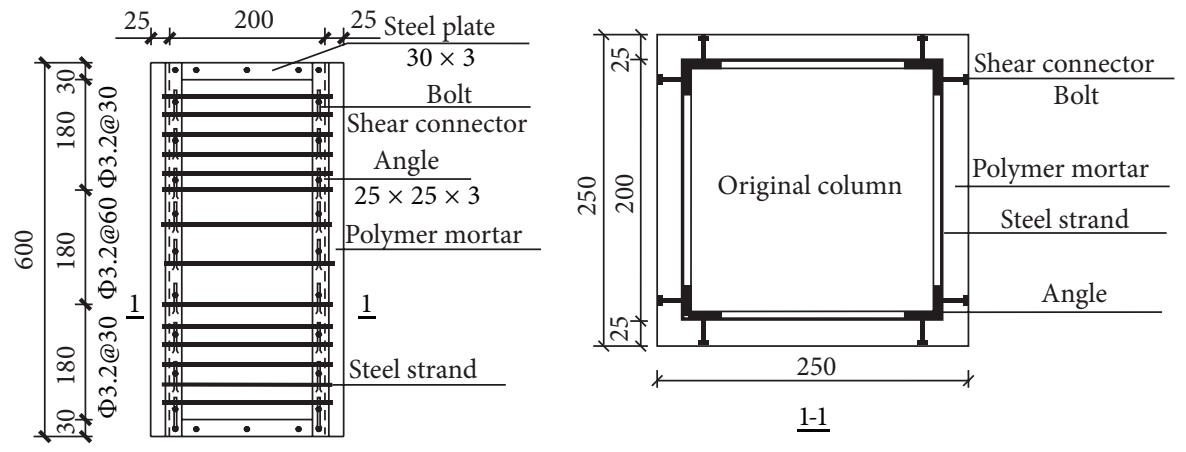

FIGURE 2: Strengthening design of the column (unit: $\mathrm{mm}$ ).

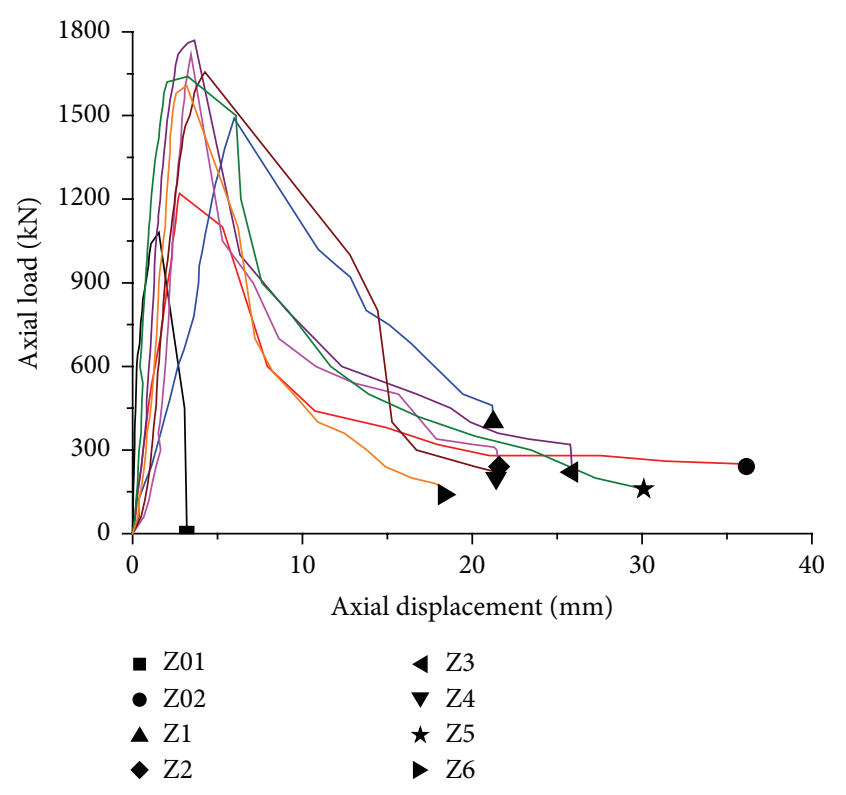

Figure 3: Load-displacement curves.

related research $[18,19]$, the bearing capacity for axial compressed specimen enhancement ratio under passive constraints decreased with the increase of the concrete strength of the original component. Thus, controlling the range of the concrete strength of the columns strengthened with HPFL and BSP is necessary.

Moreover, the ultimate bearing capacity for the strengthened columns increased with the increase of the longitudinal reinforcement ratio and stirrup reinforcement ratio of the original component. The value is in between the maximum and the minimum reinforcement ratio values.

4.2. Constraint Area of the Reinforced Layer. According to existing experimental conclusions [18-20], the constraints were uniformly distributed and equal in all directions for circular cross section columns under lateral confinement, and the strengthening effect was satisfied. By contrast, the strengthening effect on the cross section was not superior to that on the circular cross section, because the lateral confinement led to obvious stress concentrations in the four corners of the rectangular columns and the stress was

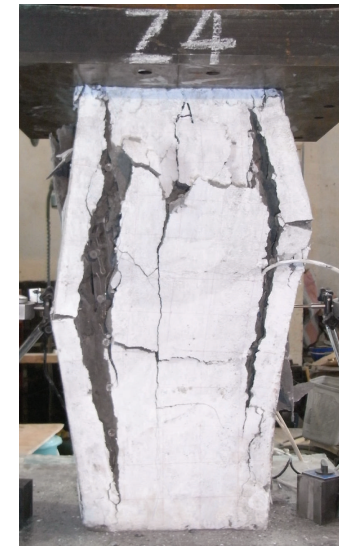

(a)

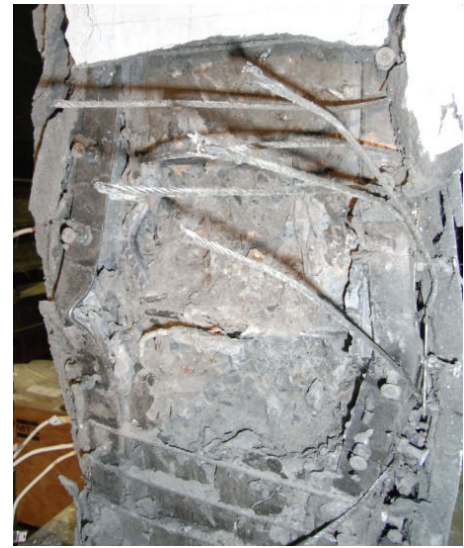

(b)
FIGURE 4: Typical failure mode of strengthened columns.

comparatively feeble in the middle of each side. Given the differences in length-to-width ratios, the lateral restraints of concrete were also different apparently. Angles were arranged in the four corners of the component; hence, if the width of the angle was larger, then the confinement area under the lateral passive restriction in the corner of the original member would be larger. The areas of the weak constraint region in the center of the sides decreased relatively. Thus, the triaxial compressive area of the cross section increased relatively.

4.3. Steel Strands. On the basis of related research $[13,18]$, the compressive strength and ultimate deformation of the component both increased with the increase of longitudinal bar ratio under lateral confinement. As a result of this increase, the ultimate bearing capacity for the strengthened columns increased significantly with the increase of the volume ratio of the high-strength steel strands. In addition, the lateral restraint of the high-strength steel strands was caused by the lateral expansion deformation of the original columns. Given that the steel strands could not hoop completely during practical construction, tension stress was small and was even approximately zero during the initiation of loading. Accordingly, the initial strain of steel strands $\left(S_{1}\right)$ was useless. When the lateral expansion deformation of the original columns started to increase, the steel strand began to 
form a passive constraint, which contributed to the effective lateral restriction; then, the strain would become effective eventually. By contrast, the steel strands were cut off by the angle, and the axial stress was close to the ultimate tensile strength. Furthermore, the steel strands did not reach the ultimate tensile strength, and the strain of steel strands was $S_{2}$. Therefore, the effective strain of steel strands $\Delta S=S_{2}-S_{1}$ could be used to limit the deformation of the core concrete effectively. Moreover, the chamfer radii of the angle bars should be increased and $S_{1}$ should be decreased to obtain a high effect of constraints.

\subsection{Bearing Capacity of the Reinforced Layer}

4.4.1. Strength and Cross-Sectional Area of the Reinforced Mortar. Recent researches by the authors in [9, 21-23] have shown that ferrocement could be used as an alternative effective technique to strengthen an RC column with inadequate shear strength or compression strength. As a result, the ultimate bearing capacity for a component could be improved. Therefore, the bearing capacity for mortar under axial load was determined by the compression strength of the mortar and the cross-sectional area. Characteristics of early strength and high strength of the polymer mortar were observed, but the thickness of the reinforced layer was only $25 \mathrm{~mm}$. If the cross-sectional area was large, then the proportion of the mortar area would be relatively small, and the contribution to the bearing capacity would be small.

4.4.2. Size and Compressive Strength of the Angle. The angle arranged at the reinforced layer was equal to the additional longitudinal steel by using section increment method; the contribution of bearing capacity of reinforced layer for the strengthened column was directly determined by the size and compressive strength of angles. However, the size of the angle should not be excessively large to avoid a large stiffness, which could affect the integrity between the reinforcement layer and the original column. Steel plates could be pasted on the sides of the column to increase the number of steel plates when the section area of the column is large.

4.4.3. Number and Size of the Bolts. The bolts located along the longitudinal direction provided the interface shear stress similar to a shear connector between the mortar and the angle, together with sticky steel glue. By contrast, highstrength steel strands were fixed by bolts, the steel plates could be formed integrally within the steel strands, and the reinforced layer could work better with the original columns. The number and size of the bolts should be limited to ensure effective interface shear and a sufficient number of fixed steel strands. Considering the bolt was connected to the steel plate by drilling, significantly large diameters of holes and too many bolts might reduce the bearing capacity for the angle.

\section{Capacity of the Strengthened Columns}

5.1. Lateral Restraint Mechanism. Traditional theory of confined concrete considered that the lateral expansion deformation of the core concrete under the axial compression

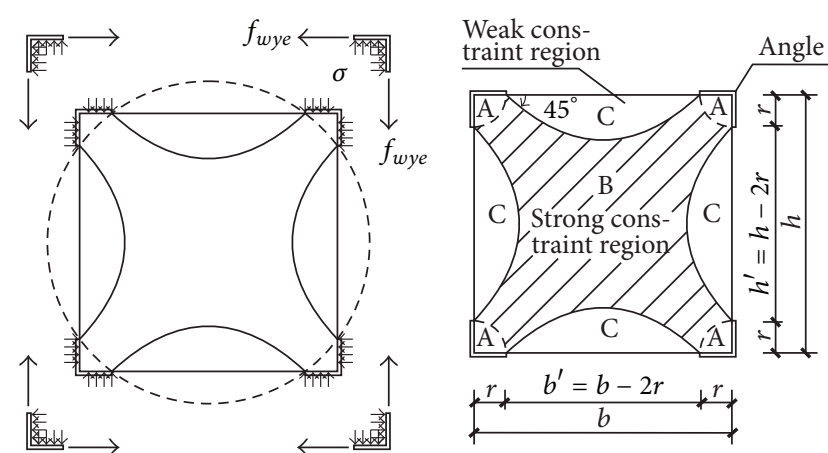

FIGURE 5: Stress distribution at the cross section of the strengthened column.

caused a horizontal bending in the straight-line segment of the stirrup; the constraint of core concrete was small because of the small bending rigidity of the stirrup. However, the stiffness was large and the deformation was small in the intersecting parts of the stirrup; the utmost restraint was formed by the resultant vertical force of stirrups, which acted on the diagonal of the core concrete. The restraint caused by the steel strands was passed through the angle to the strengthened column, as shown in Figure 5. Hence, the strong constraint region of the strengthened column was radically different from that of traditional theories. Steel strand formed the restraint stress $\sigma$ on core concrete through angle, and the strong constraint regions $\mathrm{A}$ and $\mathrm{B}$ were also formed. Meanwhile, the flexural stiffness of the steel strand was nearly zero, and region $\mathrm{C}$ was the weak constraint region of the strengthened column.

On the basis of existing research [18], the restraint stress $\sigma$ (Figure 5) was applied to the strong constraint region as an arch. The shape of arch was a quadratic parabola with an initial angle of $45^{\circ}$, and the cross-sectional area of the original column was $A_{c}=b \times h$. Accordingly, the area of the weak constraint region was

$$
A_{r}=\frac{(b-2 r)^{2}+(h-2 r)^{2}}{3} .
$$

The area of the strong constraint region was

$$
A_{q}=A_{c}-A_{r}=b h-\frac{(b-2 r)^{2}+(h-2 r)^{2}}{3},
$$

where $b$ and $h$ are the width and the height of the column, respectively, and $r$ is the width of the angle. The equations could also be used to calculate the area of the strong and weak constraint zones of the column strengthened with HPFL alone. When $r=0$, the effective coefficient of reinforced restriction was defined by $k=A_{q} / A_{c}$.

For the circular cross section, (1) was equal to zero and (2) turned to $A_{q}=\pi D^{2} / 4 ; D$ was the diameter of the original column; $k$ was 0.95 [19]. Therefore, the reinforcement effect would be improved by the increasing radii of the rounded corners for rectangular sections.

Given that the bending strength of the steel strand is much smaller than that of steel and that its stiffness equals 


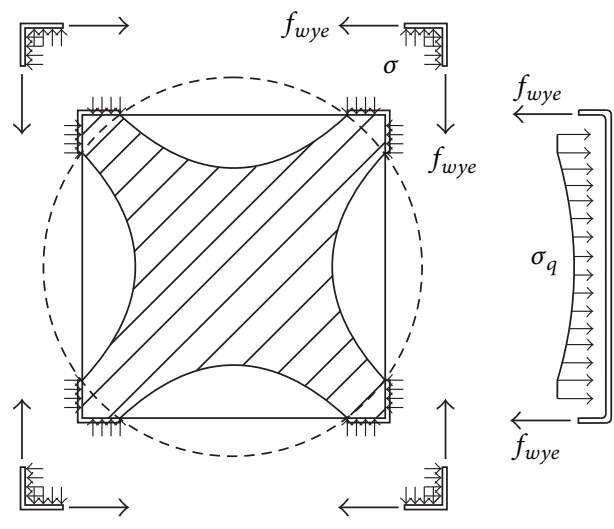

FIGURE 6: Restraint stress of cross section.

zero, the strength of concrete in the weak constraint region was not improved. The strength of concrete in this region could be considered equal to the concrete axial compressive strength $f_{c}$.

With the constrained steel strand and stirrup, the compressive strength of the concrete improved significantly under the triaxial compression in the strong constraint region. According to the study of a column confined with spiral stirrups by Richart et al. [24], the compressive strength $f_{q c}$ in this region was

$$
f_{q c}=f_{c}+k_{1} \sigma_{q}
$$

where $\sigma_{q}$ is the lateral restraint stress applied by reinforced layer, and $k_{1}$ is the stress coefficient with a value of 4.0 according to an existing research [20].

As shown in Figure 6, the lateral restraint stress was distributed equally with the scope of the angle pasting in the strong constraint region and decreases in the center of section. According to existing research [25], the stress was supposed to be distributed equally, the steel strand was considered an individual, and the equation could be determined by static equilibrium equations:

$$
2 f_{w y e} A_{w s 1}=k \sigma_{q} b s_{w},
$$

where $f_{w y e}$ and $A_{w s 1}$ are the tensile strength of steel strand and the cross-sectional area, respectively, and $s_{w}$ is the space between steel strands.

Given the stirrup in the original column, the function of the steel strand would influence the core concrete. Then, on the basis of the steel substitution principle, the stirrup could be regarded as a steel strand.

An equation was derived based on $\left(f_{w y e} A_{w s 2}\right) / s_{w}=$ $\left(f_{y v} A_{s v}\right) / s_{v}$ :

$$
A_{w s 2}=\frac{f_{y v} A_{s v}}{s_{v}} \times \frac{s_{w}}{f_{w y e}} .
$$

The cross-sectional area of the steel strand was composed of equivalent substitution and reinforcement and could be computed as follows:

$$
A_{w s}=A_{w s 1}+\frac{f_{y v} A_{s v}}{s_{v}} \times \frac{s_{w}}{f_{w y e}},
$$

where $A_{s v}, f_{y v}$, and $s_{v}$ are the original cross-sectional area, the yield strength, and the spacing of the stirrup, respectively, and $A_{w s 2}$ is the cross-sectional area of the substitution.

The concrete cover was on the surface column. Thus, the area of core concrete confined by the original stirrup was smaller than the area confined by steel strand. The smaller area of the core concrete confined by original stirrups would increase $\rho_{w}$. Accordingly, the latter had a smaller total volume ratio $\rho_{w}$ of steel strand in a column, and this smaller ratio is partially conservative for calculating the bearing capacity of the strengthened column. The equation was given as

$$
\rho_{w}=\frac{2 A_{w s}(b+h)}{b h s_{w}} .
$$

Equation (7) is substituted into (4), which obtains

$$
\sigma_{q}=2 f_{w y e} \frac{k \rho_{w} h}{2(b+h)}=\frac{k f_{w y e} \rho_{w} h}{b+h} .
$$

Modifying (8) is necessary because the lateral restraint forces decreased with the increase of the concrete strength in the original column. An impact coefficient of concrete strength $\beta_{c}$ was introduced by "design code for strengthening concrete structure" (GB50367-2006). $\beta_{c}$ was 1.0 when the concrete strength was less than C50. $\beta_{c}$ was 0.85 when the concrete strength was larger than $\mathrm{C} 80$, and other values of $\beta_{c}$ were estimated by using linear interpolation method. The tensile strength $f_{w y}$ could not be applied because the steel strand was cut off early by the angle. Thus, $f_{w y e}=\psi f_{w y}$ was introduced to reduce the tensile strength, $\psi$ was the strength reduction factor of steel strand, $\psi$ was 0.55 based on the ratio between the average strain calculated on tested data and the strain that corresponded to tensile strength, and $\psi=0.72$ if the corner of the column was chamfered and pasted with steel plate [26]. If the chamfering radius was larger than $1 / 3$ of the side length, then $\psi=1.0$. This value was the same as that of the circular cross section. Hence, (8) could be rewritten as

$$
\sigma_{q}=\beta_{c} k \frac{\psi f_{w y} \rho_{w} h}{b+h} .
$$

For the circular cross section, (7) and (9) were calculated by the following equations, where the strength reduction factor of steel strand $\psi$ was 1.0:

$$
\begin{aligned}
& \rho_{w}=\frac{4 A_{w s}}{D s_{w}}, \\
& \sigma_{q}=\beta_{c} k \frac{\psi f_{w y} \rho_{w}}{2} .
\end{aligned}
$$

5.2. Calculation Equation of Axial Bearing Capacity. The calculation of axial bearing capacity was based on the loads carried by different parts of the strengthened column.

5.2.1. Bearing Capacity of Reinforced Mortar Layer $N_{1}$. The mortar layer was equipped with the characteristics of high early strength, which supported load as a part of the reinforced structure; and the thickness of the layer of the column 


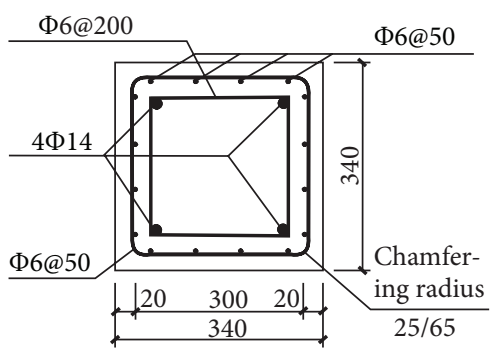

(a) Document 19

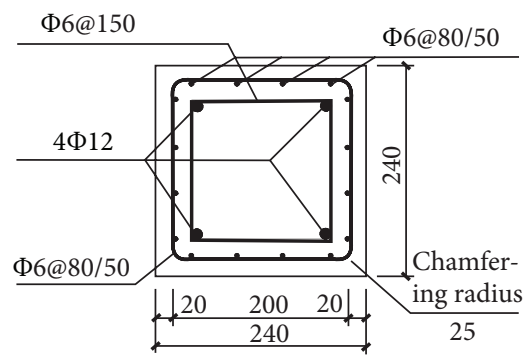

(c) Document 28

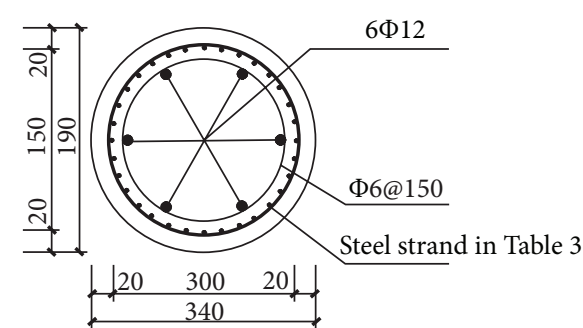

(b) Document 20

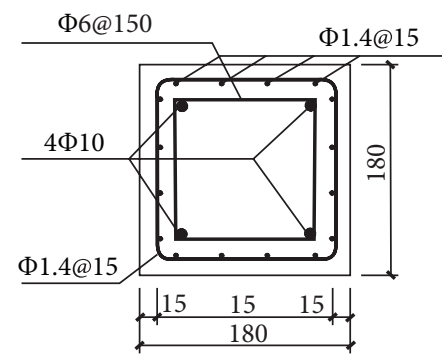

(d) Document 29

FIGURE 7: Cross sections of the strengthened columns.

strengthened with HPFL and BSP $c$ was approximately $25 \mathrm{~mm}$. The mortar layer could not contact the beam and slab on the top of columns closely under gravity. Thus, the reinforced layer could not fully and effectively bear the pressure transferred from the beam and slab. This study and another test study [17] indicated that the compressive strain of the mortar on the angle surface was much larger than that among angles because of the shear connector on the angle surface. In particular, the former was $70 \%-80 \%$ of the peak strain of the mortar, and the latter was merely around $30 \%$ of the peak strain. Furthermore, the areas of the two parts of mortar were $A_{m 1}$ and $A_{m 2}$, which were calculated by $A_{m 1}=$ $8 r c+4 c^{2}, A_{m 2}=2[(b-2 r)+(h-2 r)] c$. The former mortar effective utilization coefficient of pressure $k_{a 1}$ was 0.7 , and the latter $k_{a 2}$ was 0.3 [27]. The effective stressed area of the mortar layer could be computed as follows:

$$
A_{m}=k_{a 1} A_{m 1}+k_{a 2} A_{m 2} .
$$

The bearing capacity for mortar was

$$
N_{1}=f_{m c} A_{m}
$$

where $f_{m c}$ was the axial compressive strength of the mortar layer.

5.2.2. Bearing Capacity of Reinforced Steel Plate $N_{2}$. The compressive capacity provided by the steel plate was used to directly calculate its contribution to axial bearing capacity for strengthened column. The equation was as follows:

$$
N_{2}=f_{j y}^{\prime} A_{j y}^{\prime}
$$

where $f_{j y}^{\prime}$ and $A_{j y}^{\prime}$ are the compressive strength of reinforced steel plate and its total cross-sectional area, respectively.
5.2.3. Bearing Capacity of Longitudinal Bar of Original Column $N_{3}$. The compressive strength provided by the longitudinal bar of original column was

$$
N_{3}=f_{y}^{\prime} A_{s}^{\prime}
$$

where $f_{y}^{\prime}$ and $A_{s}^{\prime}$ are the compressive strength of the longitudinal bar in the original column and the total cross-sectional area, respectively.

5.2.4. Bearing Capacity of Restrained Zones $N_{4}$. The bearing capacity for restrained zones was composed of the strong and weak constraint zones. Thus, the bearing capacity could be calculated as follows based on the strength and compression area:

$$
\begin{aligned}
N_{4} & =f_{c} A_{r}+f_{q c} A_{q}=f_{c}\left(A_{c}-A_{q}\right)+\left(f_{c}+4 \sigma_{q}\right) A_{q} \\
& =f_{c} A_{c}+4 \sigma_{q} A_{c} .
\end{aligned}
$$

5.2.5. Bearing Capacity of the Strengthened Column N. The axial compression capacity for square columns strengthened with HPFL and BSP could be calculated by adding all parts of force as follows:

$$
N=f_{m c} A_{m}+f_{j y}^{\prime} A_{j y}^{\prime}+f_{y}^{\prime} A_{s}^{\prime}+\left(f_{c}+4 \sigma_{q}\right) A_{c} .
$$

5.3. Verification of Bearing Capacity Calculation. A total of 43 columns under axial compression were selected from this paper and another research $[19,20,28,29]$ to verify the rationality of the above equations and parameters. The reinforcement details of specimens selected from the documents are shown in Figure 7.

The strengthened section of specimens from [19] is shown in Figure 7(a), and 13 specimens were selected for calculation. 


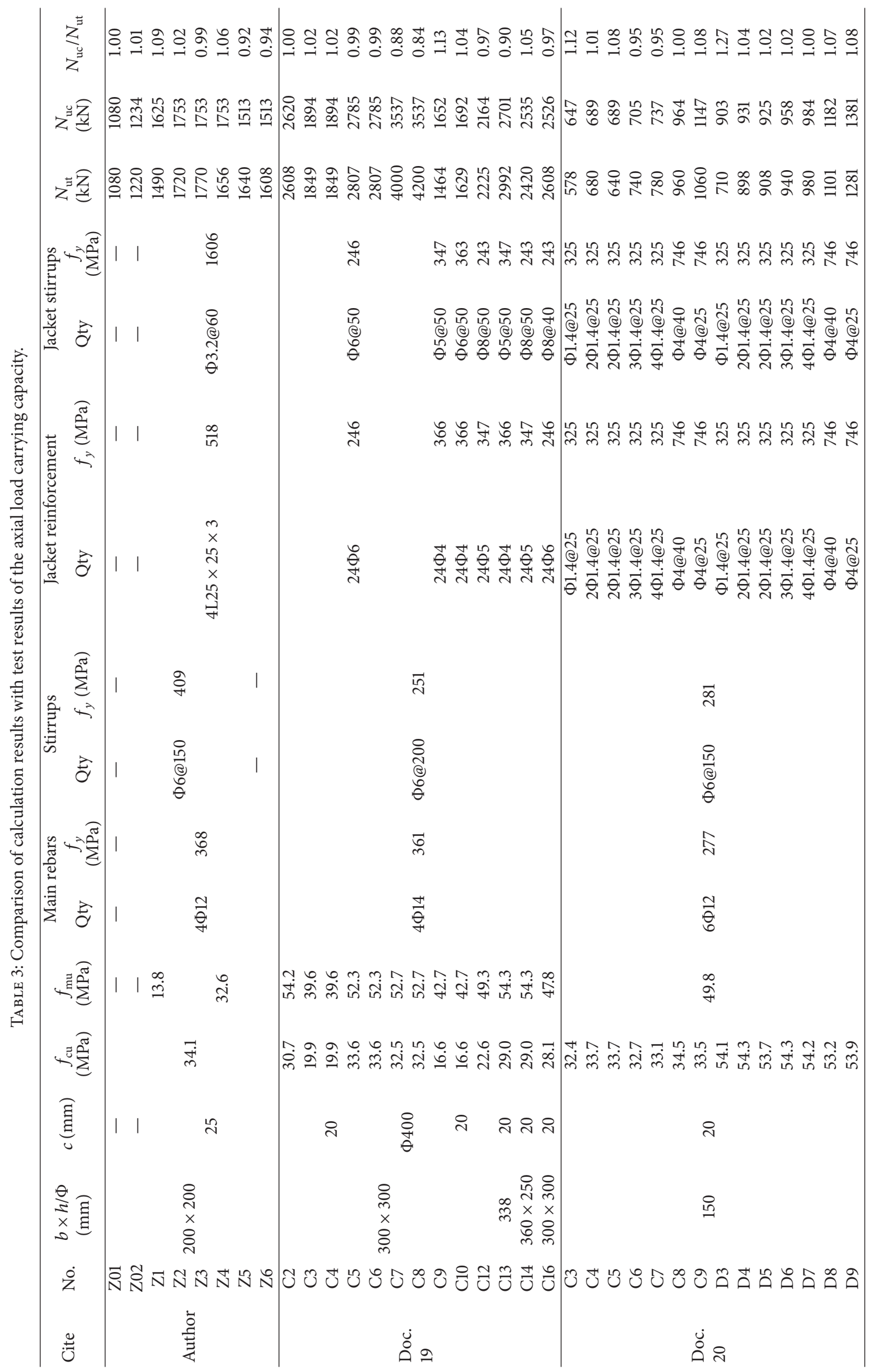




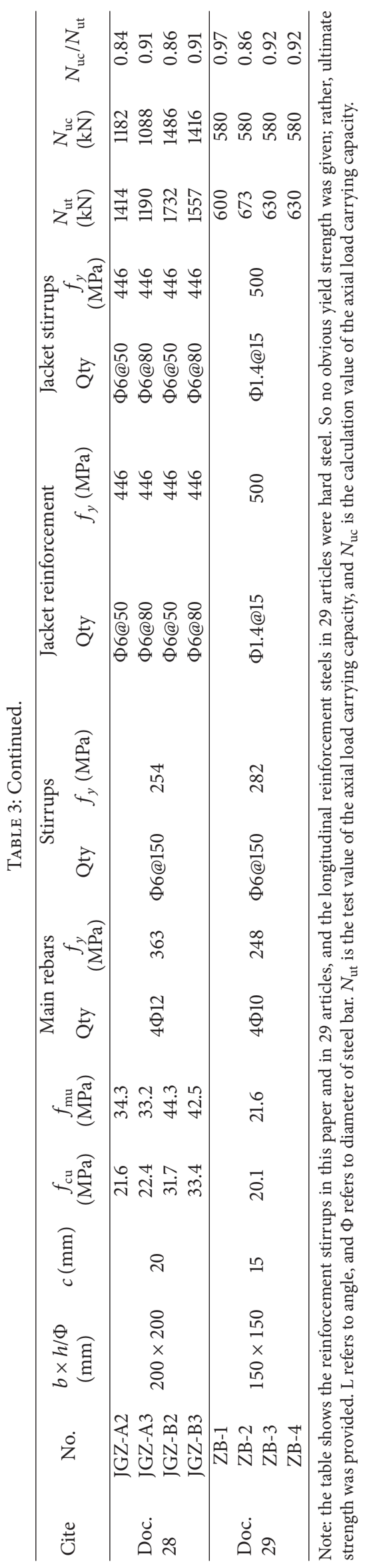


Different steel meshes with different sizes were used to strengthen columns. As shown in Table 3, the chamfering radius of C7 and C8 was $65 \mathrm{~mm}$, which was larger than $1 / 3$ of the cross section length. A total of 14 specimens selected from document [20] were all circular concrete columns; the strengthened section is shown in Figure 7(b). Strengthened wire meshes with a diameter of $1.4 \mathrm{~mm}$ were set as 1-4 layers. Different materials of specimens are shown in Table 3. A total of 4 specimens were selected from [28, 29]; the details of the strengthened section are shown in Figures 7(c) and $7(d)$. The strengthened mortar of specimens from [29] was sprayed.

The compressive capacities for the above columns are shown in Table 3 . The average ratio of the computed values to experimental values was 0.99 , the variance was 0.007 , and the coefficient of dispersion was 0.085 . Therefore, the computed results were in good agreement with the test results. The equation given in this paper to calculate the axially compressive capacity for the columns strengthened with HPFL and BSP was available. In particular, the section shape of C7 and C8 selected from [19] was circular, and the area of the reinforced layer increased to $28.4 \%$ to the entire cross section, which contributed to larger compressive capacity. $k_{a 2}$ and $k_{a 1}$ were taken as 0.7 in the calculation. The strength reduction factor of steel strand $\psi$ was 1.0 , because the chamfering radius was larger than $1 / 3$ of the cross section length. However, both calculated values were still low. This result indicated that $k_{a 2}=0.7$ was still conservative because the constraint effect and bearing capacity of the reinforcement layer increased after the tremendous chamfering. The coincidence of the computation of specimens from [20] was better because the reinforcement layer was $10 \mathrm{~mm}$ shorter than the two ends of the original column. Furthermore, the vertical load could not be acted on the reinforced layer directly. Thus, the bearing capacity for reinforced mortar layer $N_{1}$ was 0 . For the specimens from $[28,29]$, a conservative $k_{a 2}$ of 0.3 was taken. The results were more stable, because the end of the specimens in [28] leveled before the test and the strengthened mortar of the specimens in [29] were sprayed. The surfaces of the two ends were smooth, and the transferred forces were great. Therefore, the equations in the present paper have good applicability in the design of ultimate bearing capacity under different reinforcement conditions.

\section{Conclusions}

(1) The reinforcing layer of HPFL and BSP work together with the original columns as a whole, the ultimate bearing capacity increased by $22 \%-52 \%$, and the ductility improved. Increasing the strength of motor and reinforcement ratios could improve the bearing capacity of columns.

(2) When failure of strengthened columns occurred, the mortar and concrete crushed and bulged outward at the center of columns, steel strands were cut off by the bending angle, the longitudinal reinforcement buckled, stirrups were pulled off, and cracks formed mainly along the bolts in the vertical of the columns.
(3) Chamfering angle bars could avoid the early cutting off of the steel strand. The strength reduction factor of steel strand was 0.55 when the angle existed, and the value was 0.72 by chamfering the component and by pasting a steel plate. Moreover, the factor could be 1.0, similar to that of the circular cross section, if the chamfering radius was larger than $1 / 3$ of the side.

(4) When dividing the mortar layer on the steel plate surface part and between steel plate parts, the effective pressure bearing coefficient of the former was 0.7 and that of the latter was 0.3 . If the mortar layer contacted with the top and the bottom components connected with the strengthened columns closely, then the latter was the same as the former, which was 0.7.

(5) On the basis of the specimens with different cross section reinforcements and the extensive experiments, the equations in this paper are widely applicable for computing the axial compression capacity for square columns strengthened with HPFL and BSP.

\section{Competing Interests}

The authors declare that they have no competing interests.

\section{Acknowledgments}

This work was supported by the National Natural Science Foundation of China (Grant no. 51308065).

\section{References}

[1] H. Huang, S. H. He, B. Q. Liu, and T. Wu, "A strengthening structure of building," China patent, ZL201220110440.9, 2012.

[2] H. Huang, B. Q. Liu, and T. Wu, "Analysis of stiffness and cracks of shear strengthened beam with stainless steel wire mesh and polymer mortar," China Civil Engineering Journal, vol. 45, no. 3, pp. 32-38, 2011.

[3] H. Huang, B. Q. Liu, S. H. He, and T. Wu, "Calculation of shear debonding capacity of RC beams strengthened with high strength steel wire mesh," China Journal of Highway and Transport, vol. 26, no. 2, pp. 102-109, 2013.

[4] ACI Committee 549, Guide for the Design, Construction and Repair of Ferrocement, American Concrete Institute, Farmington Hills, Mich, USA, 1999.

[5] H. H. Nassif and H. Najm, "Experimental and analytical investigation of ferrocement-concrete composite beams," Cement and Concrete Composites, vol. 26, no. 7, pp. 787-796, 2004.

[6] B. Kondraivendhan and B. Pradhan, "Effect of ferrocement confinement on behavior of concrete," Construction \& Building Materials, vol. 23, no. 3, pp. 1218-1222, 2009.

[7] M. AI Kubaisy and M. Z. Jumatt, "Crack control of reinforced concrete members using ferrocement tension zone layer," Journal of Ferrocement, vol. 35, no. 1, pp. 490-499, 2005.

[8] P. Paramasivam, C. T. E. Lim, and K. C. G. Ong, "Ferrocement application in structural upgrading: an overview," ASCE Journal of Structural Engineering, vol. 32, no. 1, pp. 27-31, 2005.

[9] K. Takiguchi and Abdullah, "Shear strengthening of reinforced concrete columns using ferrocement jacket," ACI Structural Journal, vol. 98, no. 5, pp. 696-704, 2001. 
[10] A. K. Sharma and R. P. Clarke, "Hysteretic behavior of ferrocement-retrofitted clay tile walls," ACI Structural Journal, vol. 101, no. 3, pp. 387-394, 2004.

[11] G. J. Xiong, X. H. Chen, L. Q. Chen, J. Z. Yang, and G. Y. Li, "Hybrid modified ferrocement under sustained load in flowing sulphuric acid solution," Cement and Concrete Composites, vol. 26, no. 1, pp. 81-86, 2004.

[12] G. J. Xiong, X. Y. Wu, F. F. Li, and Z. Yan, "Load carrying capacity and ductility of circular concrete columns confined by ferrocement including steel bars," Construction \& Building Materials, vol. 25, no. 5, pp. 2263-2268, 2011.

[13] C. D. Zhou, X. B. Bai, F. Zhao, X. L. Lü, and C. L. Li, "Experimental study on circular concrete short columns strengthened with pre-stressed FRP under axial compression," Journal of Building Structures, vol. 34, no. 2, pp. 131-140, 2013.

[14] Y.-P. Peng, Z.-X. Liu, and M. Ma, "Analysis of axial compressive bearing capacity of square concrete columns confined with striped FRP," Journal of Wuhan University of Technology, vol. 32, no. 3, pp. 24-28, 2010.

[15] Z. X. Guo, J. Y. Zeng, Q. X. Huang, and Y. Liu, "Experimental study on axial compression behavior of RC columns retrofitted by prestressed steel jackets," Journal of Building Structures, vol. 33, no. 11, pp. 124-131, 2012.

[16] Y. Y. Lu, J. Y. Shi, and Y. S. Huang, "Bearing capacity calculation method for axially compressed RC columns strengthened with angle steel," Chinese Journal of Applied Mechanics, vol. 25, no. 4, pp. 719-723, 2008.

[17] X.-Y. Wu, F.-F. Li, Z. Yan, and G.-J. Xiong, "Axial compression performance of concrete columns strengthened by steel bar and wire mesh mortar," Engineering Mechanics, vol. 28, no. 1, pp. 131137, 2011.

[18] Y. B. Wu and G. F. Jin, "Comparative study on the design method of load bearing capacity of RC column confined by fiber reinforced polymer," Fiber Reinforced Plastics/Composites, vol. 13, no. 1, pp. 7-11, 2011.

[19] N. Xu, The Research on CMMR Strengthened RC Axial Loading Member, Hunan University, Changsha, China, 2006.

[20] L. M. Jiang, The Research on the Performance of RC Columns Strengthened with High Performance Composite Cement, Hunan University, Changsha, China, 2006.

[21] K. Takiguchi and Abdullah, "Experimental investigation on ferrocement as an alternative material to strengthen reinforced concrete column," Journal of Ferrocement, vol. 30, no. 2, pp. 177190, 2000.

[22] K. Takiguchi and S. F. Abdullah, "On strengthening and repairing of shear failure type R/C columns with circular ferrocement jacket," Journal of Structural Construction Engineering, no. 541, pp. 145-153, 2001.

[23] Abdullah and K. Takiguchi, "An investigation into the behavior and strength of reinforced concrete columns strengthened with ferrocement jackets," Cement \& Concrete Composites, vol. 25, no. 2, pp. 233-242, 2003.

[24] F. E. Richart, A. Brandtzaeg, and R. L. Brown, The Failure of Plain and Spirally Reinforced Concrete in Compression, Engineering Experiment Station, University of Illinois, Champaign, Ill, USA, 1929.

[25] J. Q. Zhang, The Mechanical Performance of Concrete Columns Confined with Fiber-Reinforced Plastics (FRP), Tongji University, Shanghai, China, 2001.

[26] W. Q. Liu, X. F. Pan, and S. G. Wang, "Ultimate bearing capacity of RC columns strengthened by composite cover of high strength wire cable mesh and polymer mortar on small eccentric loading," Journal of Nanjing University of Technology (Natural Science Edition), vol. 32, no. 1, pp. 1-6, 2010.

[27] China Planning Press, "Technical specification for strengthening concrete structures with grid rebar and mortar," CECS 2422008, China Planning Press, 2008.

[28] L. T. Bu, Y. Y. Li, C. Yuan, and J. Tao, "Experimental study on bearing capacity of PVA-ECC reinforced concrete square columns subjected to axial load," Building Structure, vol. 42, no. 7, pp. 97-102, 2012.

[29] L. Yan, Experimental as Well as Digital Modeling Research on RC Columns Wrapped with Steel Wire Meshwork and Reinforced by High Strength Mortar Spray, Xi'an University of Technology, Xian, China, 2004. 

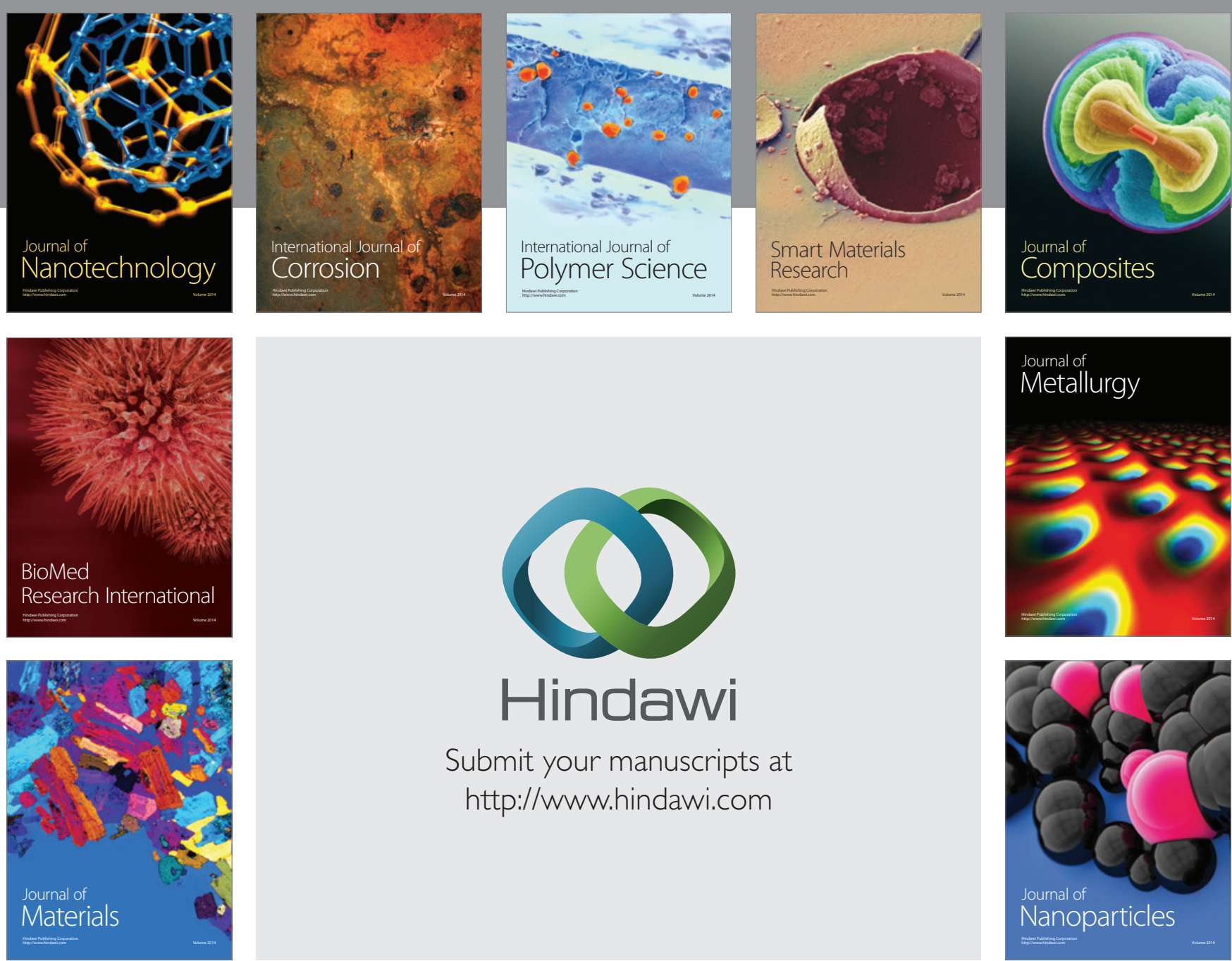

\section{Hindawi}

Submit your manuscripts at

http://www.hindawi.com

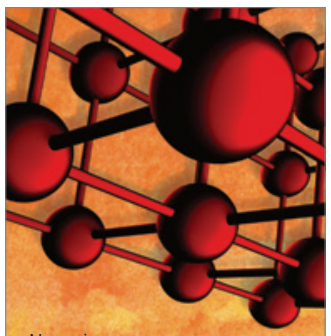

Materials Science and Engineering
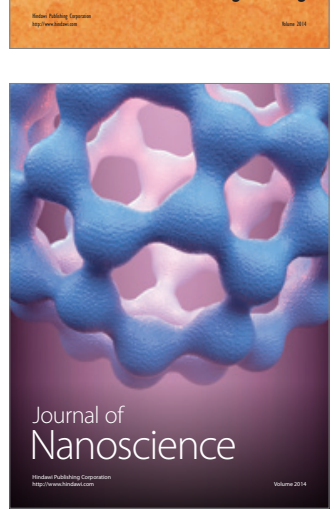
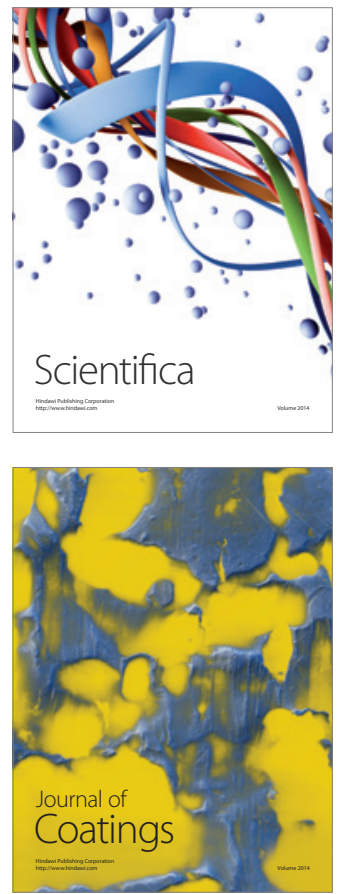
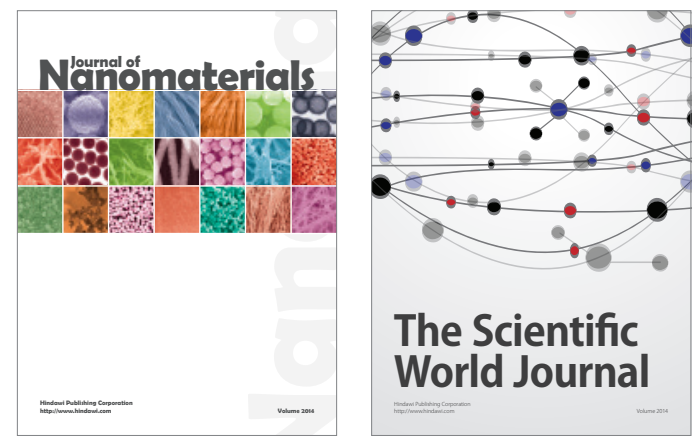

The Scientific World Journal
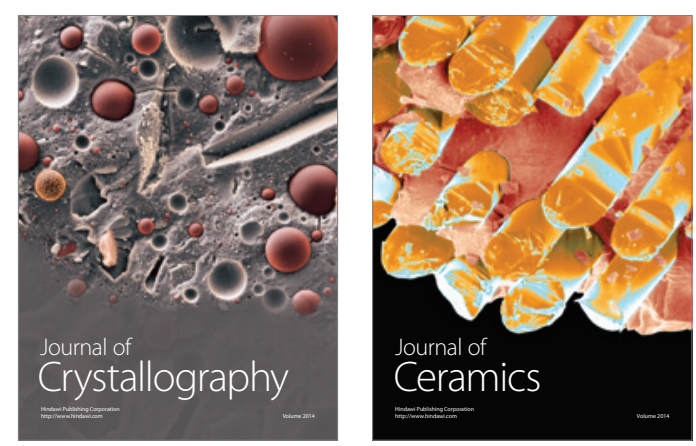
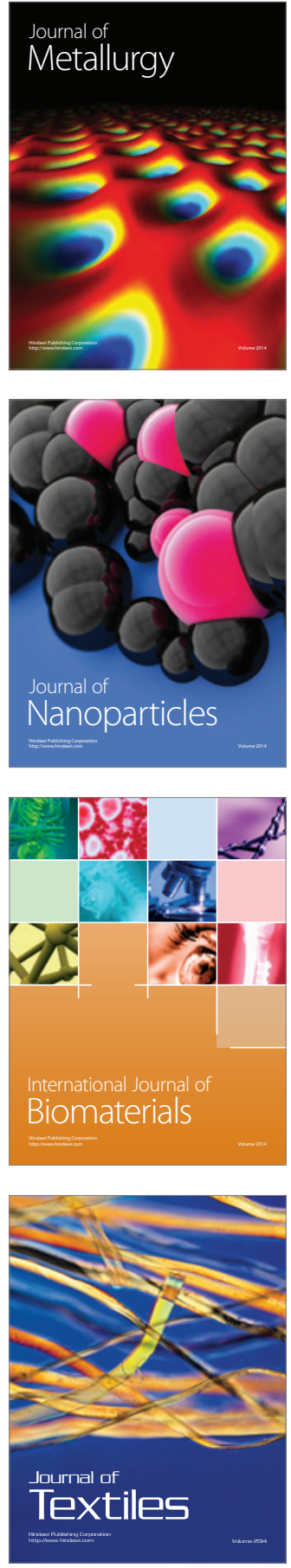